\title{
La administración del Real Situado en tiempos del gobernador Tomás Marín de Poveda: corrupción en detrimento del Ejército de Chile $(1692-1700)^{1}$
}

\author{
Antonio Luis Rodríguez Ridao ${ }^{2}$
}

Recibido: 8 de febrero de 2017 / Aceptado: 14 de mayo de 2017

Resumen. El "mérito del dinero" facultó a Tomás Marín de Poveda para ejercer los cargos de gobernador y capitán general del reino de Chile entre 1692 y 1700 . El ejército creado para la defensa de la frontera chilena, así como el Real Situado destinado a financiarlo, se convirtieron en unas de las formas de amortización de aquella considerable inversión -y fuente de otros ingentes beneficios- por parte del referido gobernador, a partir de la ejecución en torno a ellos de negocios ilícitos que convergieron en corrupción. Marín de Poveda, en complicidad con los situadistas y de buena parte de la oficialidad militar y financiera, malversó gran parte de la ayuda destinada a los soldados, los endeudó y les obligó a comprar en sus tiendas, y provocó, así mismo, el fallo en los controles de la administración mediante el uso de la violencia y la coacción sobre las instituciones. Todo ello, en definitiva, en perjuicio de las guarniciones militares chilenas y de la propia estabilidad imperial. En cualquier caso, la omisión en la remisión de varios Situados desde Potosí durante el período de gobierno de Tomás Marín de Poveda, imposibilitó que el ejército se constituyese en la única y gran vía para forjar su fortuna particular.

Palabras clave: Corrupción; ejército; situadistas; Real Situado; Marín de Poveda; Caja Real de Potosí; Chile; siglo XVII.

\section{[en] The Administration of "Real Situado" in Times of Governor Tomás Ma- rín de Poveda: Corruption to the Detriment of the Chilean Army (1692-1700)}

\begin{abstract}
The "merit of money" enabled Tomas Marin de Poveda to serve as Governor and Captain General of the Kingdom of Chile between 1692 and 1700. Marin de Poveda took advantage of the Royal Army designated for the defense of the Chilean border, and the Royal Situado destined to finance it, as means toward the amortization of the considerable investment he had made, by using them to carry out illicit dealings that amounted to corruption. In complicity with the situadistas and many of the military and financial officers, Marin de Poveda embezzled much of the subsidy assigned to the soldiers, indebted them and forced them to buy from him and his cohorts, using violence and coercion on the institutions and causing the failure of the Administration's controls; all this, ultimately, to the detriment of the Chilean military and the stability of the Empire itself. In any case, omission in the delivery of the Situado from Potosi to Chile during the time of his government made it impossible for the Army to serve as Tomas Marin de Poveda's only and grand means for private gain.
\end{abstract}

\footnotetext{
Este artículo forma parte del Proyecto Fondecyt Iniciación Chile No. 11130190. El autor agradece a los evaluadores anónimos de la Revista Complutense de Historia de América las convenientes sugerencias y aportaciones a este trabajo.

2 Universidad Autónoma de Chile - Universidad Complutense de Madrid

E-mail: antonio.rodriguez@uautonoma.cl
} 
Keywords: Corruption; Chilean Army; Situadistas; Real Situado; Marín de Poveda; Real Treasures of Potosi; Chile; 17th Century.

Sumario. 1. Introducción. 2. La infausta experiencia de los 'reales de contado': quiebra del sistema financiero militar y facilidades a la corrupción. 3. Un mercado que usufructuar: Marín de Poveda y el Ejército como fuente de lucro. 4. Provocando el fallo en los mecanismos de control: amenazas, violencia e intimidación. 5. Consideraciones finales. 6. Referencias bibliográficas.

Cómo citar: Rodríguez Ridao, A. L. (2017) La administración del Real Situado en tiempos del gobernador Tomás Marín de Poveda: corrupción en detrimento del Ejército de Chile (1692-1700), en Revista Complutense de Historia de América 43, 101-126.

\section{Introducción}

La narración clásica del gobierno de Tomás Marín de Poveda, expuesta en la magna "Historia Genera de Chile" de Diego Barros Arana3 ${ }^{3}$, ha conocido en fechas recientes un profundo enriquecimiento gracias a varias publicaciones de marcado carácter innovador, especialmente la tesis doctoral de Jimena Paz Obregón Iturra ${ }^{4}$ y la obra colectiva coordinada por Francisco Andújar Castillo y Domingo M. Giménez Carrillo acerca del origen y ascenso de una familia que alcanzó "la riqueza y la gloria en tierras americanas"5. Gran parte de estos trabajos centraron sus análisis en el estudio de las diversas facetas de Tomás Marín de Poveda en el tiempo en que ejerció como capitán general en el reino de Chile (1692-1700) y constituyen, en este sentido, el punto de partida imperativo en el desarrollo de este artículo. Al respecto, Andújar Castillo reveló el origen venal de su nombramiento, cargo que alcanzó el susodicho bajo el "mérito del dinero" abonando la considerable cantidad de 44.000 pesos de a ocho reales ${ }^{6}$. En esta línea, la propia Obregón Iturra, en un certero trabajo inserto en la misma obra, se aproximó a examinar las formas de amortización de aquella ingente inversión realizada por Marín de Poveda para la adquisición de las dignidades de gobernador y capitán general, y presidente de la Real Audiencia, del reino de $\mathrm{Chile}^{7}$; un territorio secundario en el contexto americano, distanciado de los centros de decisión política y económica, subordinado en su defensa al virreinato peruano y expuesto a la constante contingencia de las sublevaciones indígenas, pero que ofrecía, como se verá, formidables posibilidades de enriquecimiento.

Que Tomás Marín de Poveda, por su cargo de gobernador y capitán general del reino de Chile, así como por el de presidente de la Audiencia, fuese conocedor de las disposiciones reales que le inhabilitaban para tener "ninguna fuente de granjerías, ganados mayores, ni menores, ni estancias, ni labranzas, tratos de mercaderías, ni otras negociaciones, ni labores, por su persona u otras interpuestas" ${ }^{\text {, }}$, debió constituir un hecho inequívoco. Para los referidos investigadores, que el gobernador Marín de Poveda atesorase una notable fortuna, corolario, sin duda, de su participación

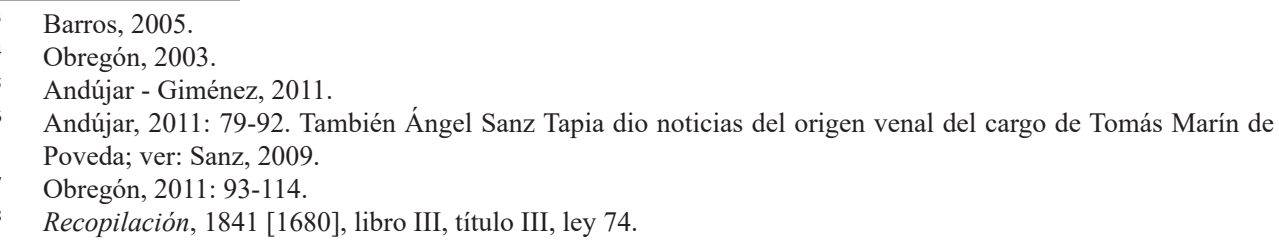


en negocios mercantiles, también. Al respecto, su juicio de residencia dio cuenta de considerables cantidades monetarias que importantes mercaderes le adeudaban como secuela de antiguos tratos comerciales. En la misma línea, su conveniente y concertado matrimonio con Juana de Urdanegui, hija del comerciante vasco afincado en Lima Juan de Urdanegui, marqués de Villafuerte, hubo de posibilitar su vínculo con una parte significativa de la élite mercantil de la capital virreinal; $y$, de hecho, fue notable el rentable negocio de venta de mulas a Potosí que acometió el gobernador junto a su cuñado, el mercader Bernardo Gurmendi ${ }^{9}$. Pero además de la red limeña, Obregón Iturra aportó algunas otras "claves y derroteros" del "encubrimiento exitoso" del gobernador, considerando el comercio basado en la venta de "piezas de esclavos" indígenas en sus internadas "tierra adentro" en el marco de la celebración de los parlamentos hispano-mapuche, así como los negocios que el gobernador implementó en torno al ejército de la frontera que capitaneaba, como dos de sus más importantes fuentes de beneficios. Es en este último punto, en la hipótesis del ejército como elemento de explotación lucrativa por parte de Marín de Poveda, en el que pretendemos centrar este trabajo, tal y como a continuación se precisará.

Casi un siglo antes del gobierno de Marín de Poveda, la férrea resistencia brindada por los pobladores nativos, principalmente en la región de la Araucanía, y con el argumento último fundamentado en la victoriosa insurrección indígena en la Batalla de Curalaba de 1598, había estimulado a las autoridades locales a suplicar a la Corona el establecimiento de un régimen militar de carácter estatal y profesional en territorio chileno. Fue así como, al año siguiente, Felipe III decidió la creación de un ejército profesionalizado ${ }^{10}$-más tarde permanente- con una planta aproximada en origen de unos 1.200 soldados -a lo largo del siglo XVII, no obstante, el número de soldados se movió en torno a los 2.000-, y que se concibió con el vital objetivo de vigilar y defender la línea de frontera que se estableció para hacer frente a las probables ofensivas de la combatiente población indígena ${ }^{11}$. La inviabilidad de financiar el sostenimiento de aquella fuerza militar permanente con los propios recursos locales, movió a la metrópoli a establecer el mecanismo fiscal para retribuir el sueldo de los soldados y satisfacer, igualmente, las obligaciones que aquel conflicto demandaba. Para ello, se fundó un Real Situado que primero se remesó desde la caja real de Lima y después, a partir de 1690, en el contexto temporal en el que insertamos nuestro estudio, desde la de Potosí. Así, desde principios del siglo XVII la caja de Concepción, "ciudad cuartel de las tropas, cabeza dirigente y brazo armado de la empresa

\footnotetext{
Andújar - Felices, 2011a: 25-28.

10 Sobre el surgimiento del ejército de Chile, ver Díaz, 2010: 79-93.

11 Al implantarse la estrategia de "guerra defensiva" instigada por el Padre Luis de Valdivia, se definió una clase de status quo geográfico a partir del cual los indígenas podrían vivir teóricamente libres en las tierras ubicadas al sur del río Bío-Bío. Posteriormente, en las Paces de Quillín -o Parlamento de Quillín- de 1641, indígenas y españoles reconocieron formalmente al río Bío-Bío como línea de Frontera entre ambas colectividades que, no obstante, lejos de permanecer aisladas, patrocinaron desde entonces un espacio de interacción e intercambio. En este sentido, se precisa hacer mención a los llamados Estudios Fronterizos, un hito historiográfico liderado por el historiador Sergio Villalobos que extinguió el secular mito de una permanente Guerra de Arauco continuada por más de tres siglos. Con esta renovación en los estudios históricos, en efecto, se dejó de conceptuar la Frontera como un espacio exclusivamente de enfrentamiento bélico, para juzgarla también como un área de interacción e intercambio cultural, comercial, de mestizaje, misional, etc. entre españoles e indígenas. Al respecto, ver: Alioto, 2014; Cerda, 1996; León, 1987, 1989 y 1992; Méndez, 1987; Obregón, 2011; Pinto, 1988, 1993 y 2015; Ruíz-Esquide, 1993; Urbina, 2009; Vásquez, 2012; Villalobos, 1982, 1989, 1992, 1995 y 2015 ; Villalobos - Pinto, 1985; Zavala, 2015; etc.
} 
conquistadora"12 chilena, debió recibir la cantidad de 293.279 pesos de a ocho reales -o lo que es lo mismo, 212.000 ducados- que habrían de ser remitidos con carácter anual desde el virreinato peruano ${ }^{13}$.

Son numerosos los autores que han hecho alusión a las prácticas que convergieron en corrupción de las que fue objeto la institución del Situado, tanto en Chile como en Perú. Así, Diego Barros Arana ya hizo mención de la "escandalosa explotación ejercida por algunos empleados superiores" 14 en la distribución de los Situados, mientras que, en la misma línea, el académico Fernando Silva Vargas se refirió a las irregularidades y a los excesos en el manejo de los caudales del Situado por parte de algunos gobernadores ${ }^{15}$. Posteriormente, en una obra de reciente publicación, y con objeto de reconstruir las redes clientelares de las cuales, en el ejercicio de su cargo, el gobernador Francisco Ibáñez de Peralta se sirvió para gestar beneficios a su familia, Silva Vargas describió también algunos de los "abusos" de aquel capitán general en lo referente al ejército de Chile ${ }^{16}$. Por último, entre otros trabajos, Jorge Abarca Aguirre abordó algunas de las prácticas corruptas manifestadas en el reino a lo largo del siglo XVII, descubriendo los desfalcos de los Situados perpetrados por el vigoroso gobernador Francisco de Meneses ${ }^{17}$.

Considerando los referentes reseñados, y partiendo de la hipótesis fijada por Obregón Iturra de que el Real Situado destinado a la frontera de Chile constituyó una de las vías de lucro con la que Marín de Poveda pudo satisfacer sus ambiciones económicas particulares, nuestro objetivo apunta a desvelar someramente los procedimientos y los negocios implementados por el gobernador para obtener un rendimiento individual en torno al ejército de la frontera; a describir de qué manera modificó las prácticas imperantes en su exclusivo favor y qué escollos hubo de salvar para ejecutarlas; aproximarnos, también, a los mecanismos de los que se sirvió para provocar el fallo en los controles de la administración; y, en última instancia, a reconocer hasta qué punto el Real Situado se erigió en la principal vía para su enriquecimiento particular.

Conviene definir, por último, el marco teórico en torno a la corrupción en el que se inserta este trabajo. Al respecto, entendemos por "corrupción" al conjunto de aquellas transgresiones a la jurisprudencia indiana (cohecho, fraude, prevaricación, soborno, malversación, abuso de autoridad, desfalcos, etc.) susceptibles de ser sancionadas, censuradas y perseguidas por la justicia, así como a la utilización y a los abusos de las funciones públicas en provecho -económico o de otra índole- de sus propios gestores. Todo ello, obviamente, en perjuicio de los administrados. Al

\footnotetext{
Campos, 1982: 31.

13 Existe una considerable producción historiográfica relativa al estudio del ejército y del Real Situado destinado a Chile. Entre otros, ver: Carmagnani, 2001; Cerda, 1996; Ferrando, 2012; Flores Guzmán, 2012; Gascón, 1998, 2000 y 2008; Jara, 1971 y 2011; Oñat, 1953; Ramón, 1978; Ramón - Larraín, 1982; Suárez, 2001; Torres, 1983; Vargas, 1983, 1984, 1987, 1991 y 1992; Vergara, 1993; Villalobos, 1992. Por lo que respecta al resto de demarcaciones territoriales de América, ver: Andújar, 2006; Celaya, 2010; Flores Morón, 1988; Grafenstein, 2000 y 2012; Irigoin - Grafe, 2008; Jara, 2011; Kuethe, 1986 y 2005; Laviana, 1980, 2000 y 2008; Marchena, 1979, 1982, 1992 y 1998; Marichal - Grafenstein, 2012; Marichal - Souto, 1994; Meisel, 2002 y 2005; Pacheco, 2005; Reichert, 2012; Serrano, 2002, 2004a, 2004b, 2005, 2006a y 2006b; TePaske, 1976; TePaske - Klein, 1982 y 1988; Wasserman, 2016.

14 Barros, 2005: 20.

15 Silva, 1968.

16 Silva, 2013.

17 Abarca, 2010.
} 
respecto, pretendemos dejar atrás la visión funcionalista del concepto de corrupción basada en la consideración del fenómeno como consustancial al Antiguo Régimen, y en consecuencia, aceptado plenamente -o no censurado- por la sociedad de aquel tiempo. Para estos autores ${ }^{18}$, el fenómeno que hoy conocemos por corrupción no era juzgado por la sociedad moderna al no existir por parte de ésta una comprensión absoluta del Derecho. Hablan de "flexibilidad", "resistencia", "oposición" y "negociación" entre la Corona y las élites americanas, y confieren a estos actos -que hoy podríamos considerar como corruptos- un carácter sistémico, hasta cierto punto, incluso, necesarios para la estabilidad del régimen. Por el contrario, de acuerdo a lo sostenido en la historiografía más reciente ${ }^{19}$, argumentamos que podemos hablar plenamente de corrupción para el periodo temporal concretado en este artículo, no sólo porque el término se reproduzca de forma explícita en la documentación de la época, sino también porque estimamos que existía una percepción clara por parte de la sociedad de los siglos XVII y XVIII acerca de las numerosas conductas ilícitas e inmorales aludidas. O lo que es lo mismo, tal y como ha argumentado recientemente la historiadora Pilar Ponce Leiva, por la existencia de un discurso condenatorio de aquellos comportamientos contrarios al "buen gobierno" implementados por diferentes agentes sociales vinculados tanto a la alta, como a la baja administración ${ }^{20}$.

\section{La infausta experiencia de los 'reales de contado': quiebra del sistema finan- ciero militar y facilidades a la corrupción}

Dadas las dificultades aducidas por los virreyes para satisfacer con todo al contado desde la caja de Lima, desde su origen el Real Situado fue remitido bajo la fórmula, más o menos precisa, de "plata y ropa por mitad", de manera que los mercaderes limeños pudieron ver en las plazas militares de la frontera chilena un mercado en el que despachar sus productos -principalmente géneros para vestir. En efecto, durante gran parte del siglo XVII se generó una amplia red de intereses comerciales en la capital virreinal en torno al Situado de Chile, de la que, tal vez, podría haberse beneficiado Marín de Poveda a partir de su ligazón con el marquesado de Villafuerte. De hecho, los referidos productos llegaron a absorber la mayor parte del Situado hasta llegar a alcanzar valores aproximados al $80 \%$ del total de la ayuda remitida a Chile en las últimas décadas de la centuria ${ }^{21}$. No obstante, los mecanismos de regulación y distribución del caudal del Situado (compra a crédito y a precios excesivos de las mercancías a los comerciantes limeños, mala calidad de las mismas, aplicación de "creces" a las mercancías en Concepción como forma de equilibrar las entradas con los gastos, pago del sueldo a los soldados en géneros y no en dinero en efectivo, etc.), evidenciaron la ineficiencia de los excedentes fiscales remesados desde Lima para satisfacer las necesidades reales de los soldados. Por este motivo, y presionada por las autoridades locales chilenas, la Corona ordenó en 1687 que el Situado de Chile fuese enviado, íntegramente, en dinero en efectivo directamente desde la

\footnotetext{
18 Bertrand, 1999; McFarlane, 1996; Moutoukias, 1988a, 1988b y 1991; Pietschmann, 1982 y 1998; Rosenmüller, 2008; Saguier, 1989a y 1992; etc.

19 Bertrand, 2011; Pietschmann, 2013; Ponce, 2016; Quiroz, 2013; Rosenmüller, 2016a y 2016b; Rosenmüller Ruderer, 2016; Waquet, 1991; etc.

20 Ponce, 2016.

$21 \quad$ Vargas, 1984: 182.
} 
caja real de Potosín 22 . Un cambio de consignación que, como manifestó el cronista Vicente Carvallo y Goyeneche en 1796, "lejos de extinguir el mal, aumentó la enfermedad"23.

Como ya se presupone, nada mejoró la fortuna de los soldados chilenos con la decisión de mudar la caja consignataria del Real Situado de Lima a Potosí. Por el contrario, al poco de arrancar la inédita coyuntura que habría de relegar a la vieja fórmula asentada en la remesa "plata y ropa por mitad" en favor del envío de la ayuda únicamente en reales de plata, los mismos partidarios que otrora clamaron en favor de aquella prometedora resolución, hubieron de descubrir que la nueva vía de subsidio al ejército terminó menoscabando, aún más, la eficacia y el estado de las plazas militares de la frontera. La razón distinguida de la nueva contrariedad hay que buscarla, como ya advirtió Álvaro Jara, en la propia naturaleza del Real Situado destinado al ejército de Chile, subordinado a la propia tributación de la Real Hacienda del virreinato a partir de las minas argentíferas de Potosí. Así, cuando aquel erario comenzó a perfilar cotas descendentes -acrecentadas a finales del siglo XVII-, la llegada de dinero a las plazas chilenas pasó por alarmantes momentos de crisis definidos por la irregularidad y la postergación en la venida de los Situados y, en consecuencia, por la existencia de años ininterrumpidos en que las guarniciones militares hubieron de subsistir impagadas ${ }^{24}$.

Al respecto de lo anterior, el virrey del Perú, conde de la Monclova, en 1698, justificó la omisión que obró en la remisión de los Situados a Chile "por la gran disminución a que con el tiempo han tenido todos los ramos de ella [de la Real Hacienda]", razón por la cual, en salvaguarda de los intereses reales, hubo de poner toda su diligencia "en conmensurar el gasto con el producto, arreglando las pagas, socorros y situaciones a lo necesario" ${ }^{25}$. Una auto-exculpación que convergió con la condescendencia del fiscal de la Real Audiencia de Chile, Gonzalo Ramírez de Baquedano, quien consideró la dificultad de que "aquellas cajas casi a un tiempo produjesen 500.000 pesos con poca diferencia para el Situado del presidio y puerto de Buenos Aires y [a la misma vez] de este ejército"26.

La persistente postergación en la remisión del Real Situado, no obstante, generó una fecunda correspondencia que reportó las desaprobaciones de las autoridades chilenas a las metropolitanas acerca de la arbitraria conducta del virrey. En este contexto, el gobernador Francisco Ibáñez de Peralta (1700-1709) informó al monarca en 1707 que "en 16 años que el Conde de la Monclova gobernó al Perú quedó debiendo 13 Situados a este ejército" 27 , mientras que tres años más tarde aseveraba que "en los ocho años de mi gobierno solo despachó dos"28. De igual forma, con anterioridad, el

22 Real Cédula de 16-I-1687. Archivo Nacional Histórico de Chile [Chile] (en adelante, ANH), Capitanía General (en adelante, CG), vol. 717, pieza 56, ff. 82-87.

23 Carvallo, 1875: 187.

24 Jara, 2011: 204-205.

25 El virrey Melchor Portocarrero Lasso de la Vega, conde la Monclova, al rey. Lima, 24-XII-1698. Biblioteca Nacional de Chile [Chile] (en adelante, BN), Manuscritos Medina (en adelante, MM), t. 235, doc. 6317, ff. 239246.

26 El fiscal Gonzalo Ramírez de Baquedano al rey. Santiago de Chile, 19-IV-1699. Archivo General de Indias [España] (en adelante, AGI), Audiencia de Chile (en adelante, Chile), 129.

27 El gobernador Francisco Ibáñez de Peralta al rey. Santiago de Chile, 24 de octubre de 1707. BN, MM, t. 172, doc. 3654, ff. 325-337.

28 El gobernador Francisco Ibáñez de Peralta al Supremo Consejo de Guerra. Santiago de Chile, 21-I-1710. AGI, Chile, 130, pieza 19. 
gobernador Marín de Poveda había refrendado reiterativas querellas ante el incumplimiento de las disposiciones reales que obligaban a los responsables financieros en Potosí a remitir el Situado en su tiempo y forma, de manera que, al final de su administración, se resignó a informar de haberse quedado debiendo al "ejército ocho años de Situado sin que haya venido más que uno en el discurso del tiempo de mi gobierno, y 107.000 pesos que envió el contador Don Juan de Esparza de la Villa de Potosí' 29 . En concreto, entre 1690, año en que llegó a Concepción el primer Situado consignado de las cajas de Potosí, y 1700, último año de gobierno de Marín de Poveda, solo se remitieron, o pudieron despacharse, tres Situados y algo más de la tercera parte de un cuarto que decidió enviar el citado contador en 1696 "para que se entregase en las cajas de Concepción sin esperar que se hiciese el entero [del Situado]"30.

Atendiendo a la coyuntura descrita, se entienden los abundantes testimonios que retrataron el asolado estado del ejército y el decaimiento y falta de disciplina de los soldados chilenos. Al respecto, "la gente de guerra reducida a una inevitable e incomprensible calamidad" ${ }^{1}$, según informó el cabildo de Concepción en 1708; "los pocos soldados desnudos [o] vestidos con los desechos de los indios", quienes, a su vez, conscientes de la flaqueza de la frontera de Chile, se percibieron a sí mismos "muy sobre sí por ver las plazas del ejército sin gentes ni pertrechos de guerra por la falta de ocho Situados", tal y como observó el capellán José González de Cisneros ${ }^{32}$; mientras que la oficialidad militar, por su parte, temiendo impotente la asolación misma del reino, se reveló con "notable lástima" ante su incapacidad de "contener [a los soldados] en sus plazas y compañías de donde es preciso que salgan a buscar algún alivio" 33 con que lograr su supervivencia. En efecto, a los manifiestos y considerables atrasos en la puntualidad de la remisión, "habiendo cinco años que los soldados de este pobre ejército no perciben ningún sueldo"34, tal y como informó en 1699 el gobernador Marín de Poveda, y al impago del entero de varios Situados que se quedarían imperecederamente debiendo, sobrevino un natural y notable decaimiento en el número de soldados -mermados a menos de 1.000 efectivos $^{35}$-, de forma que ni "los primeros puestos que fueron en otros tiempos tan apetecidos y apreciados, apenas hay hoy quien los solicite" 36 .

En cualquier caso, además de los testimonios que desvelan el desguarnecimiento de la frontera, la inacción del ejército y, en definitiva, el poco éxito obtenido con el cambio de consignación de la caja libradora, se descubren, también, otras informaciones análogas que dan cuenta de cómo la nueva coyuntura transfiguró al Real Situado de Chile en objeto de explotación y de comercio por parte de actores sociales que, haciendo caso omiso a lo que las disposiciones reales que regulaban sus dignidades les preceptuaban, contribuyeron a quebrar la disciplina y la desdichada tesitura del ejército con la ejecución de prácticas ilícitas que convergieron en corrupción en torno a la referida ayuda.

\footnotetext{
El gobernador Tomás Marín de Poveda al rey. Santiago de Chile, 23-IV-1699. AGI, Chile, 129.

El fiscal Gonzalo Ramírez de Baquedano al rey. Santiago de Chile, 19-IV-1699. AGI, Chile, 129.

Informe del cabildo de Concepción al rey. Concepción, 29-III-1708. AGI, Chile, 130.

José González de Cisneros al rey. Concepción, 20-I-1699. AGI, Chile, 129.

El maestre de campo Alonso Antonio Velázquez de Covarrubias al rey. Concepción, 23-IV-1699. AGI, Chile, 129.

34 El gobernador Tomás Marín de Poveda al rey. Santiago de Chile, 4-IV-1699. AGI, Chile, 129, pieza 25.

35 Vargas, 1987: 341; 1992: 420.

36 Memorial de Mateo Ibáñez de Segovia, marqués de Corpa, al rey (1701). AGI, Chile, 129, pieza 19.
} 
Con respecto a este punto, se precisa considerar el procedimiento seguido para la provisión y disposición del Situado. Cada año se enviaba desde Chile al virreinato un situadista para que se responsabilizase de solicitar, y luego conducir, el dinero que integraba el Situado. Desde la instauración de la ayuda en 1603, el Situado fue remitido con este situadista vía marítima desde el Callao -puerto principal de las colonias emplazado a tres leguas de la ciudad de los Reyes-, hasta el fondeadero de Talcahuano -en la bahía de Concepción-, puerto regular donde se producía el desembarque de las mercancías que eran portadas a pie a aquella ciudad que distaba dos leguas y media. Sin embargo, a raíz del cambio de consignación, se dispuso que la remisión se realizase por tierra directamente desde Potosí. Así, en observación a la nueva disposición, los situadistas hubieron de encauzar el Situado a pie por la cordillera "que es por donde trajinan los arrieros que conducen en cabalgaduras cordobanes desde aquellas provincias [de Chile] a la villa de Potosí"37, y que podía atravesarse, obviando así el impedimento de las nieves, durante los meses estivales de diciembre a marzo. La travesía se prolongaba, luego, "por la parte del despoblado que está entre Atacama y Copiapó" 38 y, haciendo tránsito por Santiago se debía alcanzar, finalmente, la ciudad de Concepción; un trayecto de 500 leguas para el que los situadistas debían hacer provisión persistente de mulas, las cuales, por su parte, tenían que "remudar muchas veces en tan largo y molesto camino [que] se necesita que sean muchas las que ha de alquilar o comprar al efecto" 39 .

En este sentido, fueron varios los juicios que maliciaron del crecimiento de la situación con respecto a los gastos que importaban los portes por mar, entre ellos el del oidor de la Real Audiencia de Santiago, Álvaro Bernardo de Quiroz, al señalar que "es aquella tierra cara" ${ }^{40}$, o el de Mateo Ibáñez de Segovia, marqués de Corpa, en un memorial dirigido al rey en 1701 donde reveló que eran "crecidos los gastos que hace el situadista por ser Potosí lugar muy caro, de gran profusión y muy expuesto a que peligren a un hombre de madurez en estos gastos que acarrea y en otros más costosos desperdicios" $"$, testimonio demostrativo de las profusas desconfianzas que generaba, además, la figura del situadista.

En efecto, la conducción desde Perú de grandes cantidades de dinero fue susceptible de transfigurarse en un mecanismo provechoso de fraude e insubordinación a la hacienda del rey, por el que los situadistas, la mayoría de ellos investidos con dignidades militares ${ }^{42}$, pudieron implicarse activamente en el mercado colonial convirtiéndose en hombres de comercio en claro detrimento y quebranto de soldados y demás oficiales del ejército ${ }^{43}$. En primer lugar, si bien el oidor Bernardo de Laya y

37 Carta de Diego Cristóbal Mesía al rey. Santiago de Chile, 20-I-1689. BN, MM, t. 167, doc. 3476, ff. $315-321$.

38 Actas de la Junta de Real Hacienda, Santiago de Chile, 22-VII-1682. ANH, Junta Superior de Real Hacienda (en adelante, JSRH), vol. 5, ff. 101-106.

39 El oidor Álvaro Bernardo de Quiroz al rey. Concepción, 2-IV-1708. AGI, Chile, 130, pieza 26.

40 Ibídem.

41 Memorial de Mateo Ibáñez de Segovia, marqués de Corpa, al rey (1701). AGI, Chile, 129, pieza 19.

42 En cuanto al origen preeminentemente militar de los consignatarios, debe interpretarse en el marco del inherente contexto de una sociedad militar de Frontera, cuyo contingente poblacional más amplio lo conformaba la propia gente de guerra con sus familias, de manera que aquellos moradores fueron, en su generalidad, a la vez, militares, hacendados, estancieros y comerciantes.

43 Esta circunstancia no fue privativa para la conducción del Real Situado chileno. Así, por ejemplo, Eduardo R. Saguier reveló cómo los situadistas comisionados para transportar el Situado desde Potosí a Buenos Aires abusaron de su cargo, en repetidas ocasiones, para lucrarse (Saguier, 1989b). De igual forma, Javier Kraselsky, en un trabajo en el que examinó los conflictos entre los comerciantes de gobierno del Consulado de Buenos Aires y sus pares en su Diputación de Potosí a finales del siglo XVIII, abordó el surgimiento del "Reglamento 
Bolívar reveló en 1690 la posibilidad de ofrendar en "pregón esta conducción para rematarse a la persona que con más utilidad de la situación la pusiere"44, la realidad de facto en el periodo que analizamos favoreció que los nombramientos de los apoderados de la ayuda imperial destinada a Chile se correspondieran, veleidosamente, a personas de confianza de los sucesivos gobernantes. Este proceder estaba fundamentado en la dificultad de hallar agentes garantes y depositarios del caudal correspondiente a los 212.000 ducados con los que avalar o restituir una eventual violación de la confianza en él consignada, "ni cuando lo hubiese es creíble que quisiese sujetarse a este encargo" 45 , desprendiéndose, en consecuencia, la reducida infalibilidad y riesgo de la conducción.

Volviendo al memorial del marqués de Corpa, éste especuló con la posibilidad de que los situadistas hubiesen actuado también como prestamistas bajo el soporte del capital monetario que custodiaban una vez percibido de los oficiales reales de la caja de Potosí. Así, denunciando la dilación en la entrega del total del monto del Situado en esta ciudad al situadista, y dado que ésta se hacía de forma fraccionada a medida que el caudal se iba reuniendo en la caja benefactora, advirtió el marqués cómo este proceder despertó en estos regentes de la plata "la codicia de interesarse con estas porciones en algún adelantamiento, que procuran [...] a personas en quienes por más que a él le parezcan abonadas, o que en efecto lo sean, no se evite el riesgo de perderlas, pues ninguna vive preservada de los contrarios accidentes que suele producir en su variedad el tiempo", y que, de hecho, añade, en diferentes circunstancias fueron, finalmente, "irreparables en la cobranza"46 en manifiesto quebranto del ejército.

Tales prácticas irregulares orientadas a los negocios lucrativos en torno al Situado por parte de los situadistas no fueron privativas, sin embargo, del periodo que examinamos. De esta manera, fueron percibidas ya por el virrey Melchor de Navarra y Rocafull, duque de la Palata, en 1682 -momento en que la ayuda llegaba, en su mayor parte, en mercaderías-, quien excusando ante el monarca la licitud de los despachos que se producían en Lima con respecto al Situado, no vaciló en inculpar a los situadistas el estado de descrédito que fue procurándose la subvención, "porque si viene el situadista para entregarse de los géneros y este se hace mercader y compra por su cuenta y lo lleva todo con una marca podrá en la entrega trocar los fardos", malogrando así, según el virrey, "todo el cuidado que aquí [en la capital virreinal] ponen los ministros" $"$. No obstante, el cambio de consignación de la ayuda a la caja de Potosí, su expedición exclusiva y en tan gran cantidad en moneda efectiva, los mayores tiempos de maniobra inherentes a la referida dilación en la entrega en aquella ciudad y de su remisión por tierra, $\mathrm{y}$, en definitiva, el menor número de personas implicadas en la conducción misma -y, por tanto, a la casi inexistencia de controles efectivos-, favorecieron, sin lugar a dudas, las observadas transacciones de carácter ilícito. Y de esta forma, el mencionado oidor Álvaro Bernardo de Quiroz, apenas seis años después de que llegase el primer Situado desde Potosí, ya advirtió al rey acerca

de situadistas" surgido, precisamente, para erradicar los abusos en la conducción de caudales (Kraselsky, 2016). Por último, y para el mismo contexto geográfico, Martin L. E. Wasserman aludió también a la conducción del Situado, considerándola un mecanismo a partir del cual los situadistas pudieron contar con dinero en efectivo para la realización de transacciones comerciales en el itinerario (Wasserman, 2016).

44 El oidor Bernardo de Laya y Bolívar al rey. Santiago de Chile, 30-IX-1690. AGI, Chile, 129.

45 Memorial de Mateo Ibáñez de Segovia, marqués de Corpa, al rey (1701). AGI, Chile, 129, pieza 19.

46 Ibídem.

47 El virrey Melchor de Navarra y Rocafull, duque de la Palata, al rey. Lima, 19-IV-1699. AGI, Chile, 129. 
del inconveniente de "convertir los situadistas en mercaderías el caudal de vuestro Real Situado que se les entrega en plata en las reales cajas de Potosí" que acontecía, sustentaba el oidor, "por conducirse la situación de este ejército en plata" ${ }^{48}$. De igual forma, el jurista Gonzalo Ramírez de Baquedano, reiterando la misma inconveniencia de que el Situado viniese por tierra y en metálico, validó a su compañero en 1699 confirmando la inclinación de los situadistas a "convertir en usos propios el caudal del Real Situado"49. Por último, considerando el hecho preciso a partir de la experiencia de más de tres lustros, Bernardo de Quiroz reafirmó, en 1708, “el que los situadistas han venido con mucho menos de los 112.000 pesos que importa la situación, por haberla convertido en usos propios, y por mas apremios que han tenido, no se les ha podido cobrar toda la falta" ${ }^{50}$.

En el mismo informe, por otra parte, el oidor imputó complicidad a los propios gobernadores en las indebidas operaciones implementadas por los situadistas, con unas palabras que resultan, en este sentido, de una claridad y profundidad definitiva: "Después de que los Situados vienen de Potosí en plata la experiencia ha enseñado que vuestros gobernadores tienen más mano en ellos que antes para poderos defraudar, pues remiten persona de su confianza que los conduzca y después que entra el caudal en poder de ésta, lo reparte para los fines que considera el gobernador" 51.

En línea con esta concluyente declaración, Abarca Aguirre da cuenta de cómo algunas décadas antes también el gobernador Francisco de Meneses había desfalcado considerables cantidades -en dinero y en mercancías, y sin justificación legítima que lo respaldara-, de los Situados remitidos entre los años 1665 y 1668, que llegaron bajo la custodia de diferentes situadistas comisionados por él que actuaron como cómplices, junto a los oficiales reales de Concepción, de los negocios que implementó el gobernador consumiendo aquellas partidas en rédito propio ${ }^{52}$. Por lo que respecta al gobernador Tomás Marín de Poveda, y entre otras muchas testificaciones querellantes que revelaremos a continuación, el virrey del Perú, conde de la Monclova, no dudó en delatar con causticidad y sarcasmo "lo interesado" que estaba en que se remitiesen "con puntualidad los Situados" 53 , mientras que la Real Audiencia de Chile, más expedita que el virrey, elucidaba que el "lastimoso desconsuelo de ver defraudarse con tanto desahogo la Real Hacienda" nacía "de permitirlo o mandarlo vuestro gobernador y capitán general al situadista y oficiales reales" ${ }^{\text {" }}$. Una enviciada conducta que volvió a repetirse a principios del siglo XVIII, igualmente por el gobernador Francisco Ibáñez de Peralta ${ }^{55}$, y que evidencia, en definitiva, las posibilidades de comercio que ciertos gobernadores otearon a partir de a sus competencias en el manejo del Situado.

\footnotetext{
$48 \quad$ El oidor Álvaro Bernardo de Quiroz al rey. Santiago de Chile, 30-IV-1696. BN, MM, t. 169, doc. 3522, ff. 199209.

49 El fiscal Gonzalo Ramírez de Baquedano al rey. Santiago de Chile, 19-IV-1699. AGI, Chile, 129.

50 El oidor Álvaro Bernardo de Quiroz al rey. Concepción, 2-IV-1708. AGI, Chile, 130, pieza 26.

51 Ibídem.

52 Abarca, 2010: 133-134.

53 El virrey Melchor Portocarrero Lasso de la Vega, Conde la Monclova, al rey. Lima, 24-XII-1698. BN, MM, t. 235, doc. 6316, ff. 229-238.

54 Informe de la Real Audiencia al rey sobre el reparto del Situado de 1695. Santiago de Chile, 30-IV-1696. AGI, Chile, 129.

55 Silva, 2013: 233.
} 


\section{Un mercado que usufructuar: Marín de Poveda y el Ejército como fuente de lucro}

Tomás Marín de Poveda partió hacia América vía Buenos Aires en septiembre de 1690 , donde permaneció durante casi un año ${ }^{56}$. Hizo irrupción en la ciudad de Santiago "intrépido y violento con gran cargazón de ropa que trajo de Buenos Aires" el 3 de enero del año siguiente, entrevistándose a su llegada con el situadista Alonso de Espejo que conducía el Real Situado correspondiente al que se había dejado de enviar de Potosí el año ya pasado de $1689^{57}$. Arribando el situadista en marzo a la ciudad de Concepción con el caudal del Situado, y Marín de Poveda en mayo con la encomienda de presidir la Junta de Hacienda ${ }^{58}$ que habría de conformarse para la distribución del mismo de acuerdo con lo regulado en la Instrucción decretada para tal fin en $1687^{59}$, ordenó el gobernador a la veeduría general reconociese lo que le tocaría en concepto de sueldo a cada soldado si aquel Situado se repartiese, previo descuento de los gastos forzosos contraídos con los asentistas y proveedores del ejército. Y viéndose que "se hallaba tan empeñado el ejército así de las contribuciones que tiene como de gastos precisos e inexcusables para mantenerle [...] que pagándose estos forzosos empeños [...] no llegaba el sueldo que les pudiera tocar a los soldados a 15 pesos" $^{60}$, el gobernador decidió "omitirlo [el Situado] hasta que llegase otro que ya se tenía noticia estaba para entregarse en Potosí" ${ }^{\prime 61}$. Es decir, con una pretensión especulativa, como ahora se verá, el gobernador suspendió la distribución de aquel Situado a la espera de juntarlo con el que se tenía comunicación llegaría en custodia del situadista José Moreno en los meses venideros. Una determinación que, lejos de manifestarse racional y convincente, generó recelos y temores entre los valedores de la Hacienda Real, y que inauguró, además, la considerable nómina de atropellos y negocios ilícitos que Marín de Poveda emprendió durante el tiempo de su gobierno en Chile. Años más tarde, ante el referido proceder del gobernador, el mismo Consejo de Indias sugirió al monarca, sin éxito, sancionar al gobernador "gravemente porque aquella detención sería sin duda de mayores empeños a los pobres soldados y en grave perjuicio de ellos", discerniendo, además, que aquella maniobra debía presumirse "por estar trabajando [el gobernador] aquel caudal en tratos y contratos para las crecidísimas utilidades de los cooperantes en aquella detención" ${ }^{62}$.

La unión de ambos Situados -el que paralizó el Gobernador y el conducido por el situadista José Moreno- se produjo 10 meses después, en enero de 1693, habiendo llegado el segundo de ellos, no obstante, "con 68.000 pesos menos que de orden de vuestro gobernador", informó el tesorero de la real caja de Concepción, Mateo

$56 \quad$ Andújar - Felices, 2011a: 25.

57 El tesorero Mateo del Cajigal y Solar al rey. Purapel, 1-VI-1695. ANH, Real Audiencia (en adelante, RA), vol. 2712, pieza 6, ff. 169-176.

58 La Junta de Hacienda para la distribución del Real Situado estaba presidida por el gobernador y conformada, además, por los oficiales de la caja real de Concepción, por el veedor general del ejército, así como por el oidor más antiguo y el fiscal de la Real Audiencia de Santiago.

59 Instrucción para la distribución del Situado de Chile. Madrid, 14-IV-1687. ANH, CG, vol. 717, pieza 56, ff. 84$86 \mathrm{v}$.

60 En aquel tiempo, el sueldo asignado a los soldados de infantería era de 105 pesos, mientras que los de caballería eran retribuidos con 132 pesos.

${ }^{61}$ El gobernador Tomás Marín de Poveda al rey. Concepción, 16-XI-1692. BN, MM, t. 168, doc. 3530, ff. 142152 .

62 Informe del Consejo de Indias al rey. Madrid, 12-IV-1695. BN, MM, t. 168, doc. 3504, ff. 152-164. 
del Cajigal y Solar, "se remitieron a Buenos Aires para pagar la mayor parte de la cuantiosa memoria de ropa que compró allí", a los que habría de agregarse, también, "otros 14.500 [pesos] que había sacado en Santiago del antecedente, los 6.000 de ellos por mano de don Antonio de Poveda, su hermano, que los pidió al situadista don Alonso de Espejo". Todo lo cual, en definitiva, concluía el tesorero, sumaban "82.500 pesos extraviados"63.

Con respecto a la ropa que el gobernador trajo de Buenos Aires y que fue abonada, como se ha descrito, con las referidas cantidades libradas de los dos Situados, Marín de Poveda dio órdenes precisas a los cabos y oficiales de las diferentes plazas militares de la frontera chilena para que dispensasen y suscribiesen boletas a los soldados con las que pudieran adquirir a crédito los géneros con los que cubrir su vestuario y alimentación. Las boletas, en este sentido, si bien actuaron como fianzas y soporte de crédito a los soldados, también se transfiguraron en instrumentos justificativos del referido empeño con las que los acreedores -como se verá, en su mayoría, podatarios del gobernador-, a la llegada de los Situados, pudieron percibir en metálico las cuantías que se les adeudaban ${ }^{64}$. De lo que se desprende, en primer lugar, la corruptibilidad con la que actuó la oficialidad militar, que lejos de entorpecer los desmanes del gobernador en el cumplimiento de sus deberes, toleró los abusos bajo el aval de un rédito individual. Y, en segundo lugar, la existencia de un mecanismo subsidiario de financiación que supuso, en última instancia, que la retribución en moneda a los soldados como parte de sus sueldos, a la llegada de los Situados, pasase a integrar las arcas privadas de quienes los habían abastecido. De esta forma, en definitiva, se garantizaron de cobrar en metálico la venta de unos productos que con dificultad hubieran rematado en el comercio ordinario de aquella región.

En cualquier caso, y a pesar de la prohibición que tenían los gobernadores de tener negocios, Marín de Poveda practicó un comercio encubierto estableciendo tiendas propias en todas las plazas militares de la frontera, administradas, eso sí, por sus más estrechos colaboradores, y en las que "empeñó", en la forma referida, a los soldados ${ }^{65}$. En este sentido, en 1694, conocedores de los excesos cometidos por Marín de Poveda, oidores y fiscales de la Real Audiencia de Chile acordaron levantar pesquisa secreta sobre los procedimientos del gobernador "para efectos de informar a su majestad, a su Real Consejo Supremo de Indias y al excelentísimo señor virrey", llamando para ello a declarar a "testigos que hubiese en dicha plaza"66. Al respecto, el capitán Juan de Cisneros y Mendoza reconoció ante Álvaro Bernardo de Quiroz la existencia de una "tienda rotulada con el nombre de Antonio Marín de Poveda, hermano de dicho gobernador" -confidente y enormemente favorecido en sus negocios mercantiles durante los años de gobierno de Marín de Poveda-, así como otras a nombre de Juan Baeza, Jerónimo Prieto, Juan de Espineda y el mismo Alonso de Espejo, entre otros. Informó este testigo, de igual forma, como en el año

63 El tesorero Mateo del Cajigal y Solar al rey. Purapel, 1-VI-1695. ANH, RA, vol. 2712, pieza 6, ff. 169-176.

64 Esta ventaja fue observada ya por Martín L. Wasserman para el Río de la Plata. Al respecto la demora y la irregularidad en el envío de los Situados desde Potosí, sirvió para propiciar un mecanismo de endeudamiento a los soldados por parte de los mismos comerciantes de la región o de los oficiales militares de superior rango de aquel presidio. De esta forma, a la llegada de los Situados, estos últimos pudieron embolsar en dinero en efectivo la venta de unas mercancías que difícilmente hubieran obtenido a través de la venta ordinaria de esos mismos productos en sus tiendas. Wasserman, 2016.

65 Obregón, 2011: 111.

66 Pesquisas sobre los procedimientos del Sr. Thomas Marín de Poveda. Santiago de Chile, 1694. ANH, RA, vol. 2844, pieza 2, ff. 119-180. 
1692, antes de la llegada del Situado conducido por José Moreno, el gobernador "dio boletas a dichos soldados para que ellos las llevasen a sacar la ropa contenida en dichas boletas, enviando unas a sus tiendas y otras a las de otros mercaderes", si bien, al año siguiente, con la llegada del Situado, añadió el declarante, "no dejó arbitrio a dichos soldados el elegir tiendas para sacar ropa y sin darles dichas boletas a dichos soldados [...] envió con ellos un ayudante para que los lleve a la tienda de dicho gobernador" ${ }^{\prime \prime}$.

En la misma línea, el testigo Luis de Oria, alférez del Real Ejército, confirmando la existencia de tiendas por toda la frontera de Chile donde el gobernador "vendía por interpuestas personas", y aludiendo a los soldados que no habían contraído empeños, afirmaba cómo a éstos "les quitaba el dicho señor presidente la plata y los enviaba a sus tiendas diciendo a su mercader que los vistiese" ${ }^{98}$. En definitiva, la necesidad del soldado de vestirse, el no poder eximirse aquel estamento militar de pasar por los almacenes del gobernador y, en suma, el exceso de precios que éste señalaba a cada uno de los géneros, permitió a Marín de Poveda quedar eventualmente dueño del Situado ${ }^{69}$. Un proceder que, en última instancia, inauguró también la larga serie de hostilidades entre Marín de Poveda y el cabildo de Concepción -especialmente en lo concerniente a la exportación de trigo ${ }^{70} \mathrm{y}$ en los que la institución se erigió en la valedora de los derechos de la élite mercantil local que hasta ese momento había ostentado la preeminencia en el abastecimiento regional del ejército fronterizo; hacendados y estancieros de la región, en efecto, hubieron de resignarse ante la arbitraria y desleal competencia impuesta de facto por el gobernador en beneficio exclusivo de su actividad privada ${ }^{71}$.

En definitiva, con el capital monetario desfalcado de los Situados conducidos por los situadistas Pedro de Espejo y José Moreno, el gobernador Marín de Poveda, en complicidad de buena parte de la oficialidad militar y de los propios situadistas, logró abonar la ropa y otros géneros que él mismo había remesado desde la ciudad de Buenos Aires, coaccionando a las instituciones y a los responsables financieros del Situado que pudieron entorpecer sus desmanes, como a continuación se verá, y eludiendo, en suma, las disposiciones reales y todos los posibles mecanismos de control indianos. Luego, mediante la imposición de un mecanismo de endeudamiento a los soldados a partir de los puntualizados "abonos" -previa suspensión de la distribución de un Situado que hubo de posibilitar la puesta en marcha del engranaje crediticio- y apremiando a los militares de las distintas plazas de la frontera de Chile a comprar en las tiendas de su propiedad -administradas, no obstante, por su red de prosélitos-,

67 Declaración del capitán Juan de Cisneros y Mendoza. Santiago de Chile, 17-II-1694. ANH, RA, vol. 2844, pieza 2, ff. 123-132v.

68 Declaración del Alférez Luis de Oria. Santiago de Chile, 20-II-1694. ANH, RA, vol. 2844, Pieza 2, ff. 132v.145 .

69 Entre otros casos similares, en un artículo de reciente publicación Alexandre Coello de la Rosa ha dado cuenta de los "excesos" del gobernador y capitán general de las Islas Marianas Juan Antonio Pimentel (1704-1717), "uno de los administradores más corruptos del siglo XVIII filipino". Así, al igual que Marín de Poveda, Pimentel endeudó a los soldados que capitaneaba y se apropió de sus sueldos vendiéndoles toda clase de productos sacados de sus propias tiendas a precios desmesurados (Coello, 2014).

70 Al respecto, Obregón Iturra apuntó cómo en el contexto de la prohibición a la exportación de trigo dispuesta por el cabildo de Concepción a los hacendados de la región, Marín de Poveda permitió subrepticiamente la remesa del cereal, percibiendo, consecuentemente, un porcentaje de los beneficios del negocio por cada fanega fletada. En Obregón, 2011: 111.

71 Ibídem: 110-111. 
alcanzó a apropiarse de las remuneraciones de los soldados. Con ellas, en primer lugar, dio pagadero a la deuda en la caja de Concepción y, en segundo lugar, obtuvo, igualmente, un rendimiento o ganancia particular. Dicho de otra forma, con el dinero del soldado pagó la ropa, liquidó lo debitado al resto de acreedores privados del ejército y se apropió del resto del caudal en base a los crecidos precios que impuso a sus ventas.

Tanto Marín de Poveda como el ejército de Chile, hubieron de esperar al año 1695 para la distribución del siguiente Situado que llegó a las cajas de Concepción, correspondiente al que se había dejado de enviar en 1691. En aquel caso, sin embargo, la confabulación no salió tal cual hubiera podido esperar el gobernador: el situadista comisionado, José Moreno, fue hallado culpable y condenado "por la cantidad de pesos que faltaron [50.050 pesos y seis reales] y dejó de entregar del Real Situado que a su cargo trajo de las reales cajas de Potosí" y que convirtió "en otros usos sin temor de la justicia y en grave perjuicio de la Real Hacienda", principalmente, para la compra de ropa de Castilla y otros géneros que habrían de ser vendidas en el mercado militar de Concepción en las tiendas del gobernador de acuerdo al procedimiento anteriormente descrito. El citado conductor incurrió, igualmente, en el grave delito de entregar certificación falsa -aceptada, como se verá, por el tesorero Mateo del Cajigal y Solar- de los gastos que con el dinero del Situado libró a varios acreedores del ejército, algunos de los cuales testificaron, contrariamente, no haber percibido lo contenido en aquella relación. Tal es el caso, entre otros damnificados ${ }^{72}$, del capitán Martín de Ugas, quien declaró no haber "recibido la cantidad de los 1.370 pesos que se refieren en dicha partida"73, así como del capitán Pedro Gutiérrez de Espejo, quien, habiendo sido abonado en géneros por el valor de los 2.000 pesos que se le adeudaban, sospechaba, sin embargo, "le [había] de estar debiendo algún resto el dicho capitán José Moreno respecto de que los géneros que le entregó no importaban la cantidad" "74 consignada en la referida certificación. Depuesto de su oficio de "contador entre partes", embargado de bienes y papeles -los cuales revelaron sus redes clientelares, vitales, a la vez, para la resolución del sumario-, y llamado por edictos y pregones "por no haberse hallado" para su ingreso en prisión, el situadista huyó durante meses de la justicia, refugiándose en este tiempo en el convento de Nuestra Señora de la Merced de Santiago.

En cualquier caso, satisfecha la tasación de los bienes embargados y recaudadas las deudas que ciertos mercaderes habían adquirido con José Moreno, la Junta de Real Hacienda de Santiago dio cuenta de la recuperación de lo defraudado por el situadista $^{75}$. En esta coyuntura, el oidor Álvaro Bernardo de Quiroz remitió la causa al fuero militar para que fuese el gobernador quien dictara sentencia, razón que explica que el expediente generado se encuentre ubicado en la actualidad en los fondos de Capitanía General y no en los de la Real Audiencia. Fue entonces, un año y medio después de iniciada la causa criminal contra el situadista, cuando José Moreno se

72 También los testimonios de Bernardo de Lesa, de Juan de Ugarte y de Francisco de Rojas. Santiago de Chile, 16-26-III-1695. ANH, CG, vol. 855, pieza 19, ff. 36-45.

73 Declaración del capitán Martín de Ugas ante el oidor Álvaro Bernardo de Quiroz. Santiago de Chile, 17-III1695. ANH, CG, vol. 855, pieza 19, ff. 40-40v.

74 Declaración del capitán Pedro Gutiérrez de Espejo ante el oidor Álvaro Bernardo de Quiroz. Santiago de Chile, 22-III-1695. ANH, CG, vol. 855, pieza 19, ff. 44-44v.

75 Copia de las Actas de la Junta de Real Hacienda. Santiago de Chile, 9-XII-1695. ANH, CG, vol. 855, pieza 19, ff. 281-283v. 
presentó en prisión, justificando su evasión a la justicia por haberse visto "falto de salud" y "temiendo que la prisión agravase [su] enfermedad" en el interín en que disponía de los medios para satisfacer el alcance desfalcado ${ }^{76}$. Marín de Poveda, considerando el reintegro de lo malversado y la falta de salud del reo -al fin y al cabo, su antiguo cómplice- valoró, entonces, dar al situadista provisionalmente la "ciudad por cárcel" "77. Finalmente, la causa militar feneció con una multa de 2.000 pesos y con una condena de dos años de destierro sobre el antiguo situadista ${ }^{78}$, lo que suscitó las quejas de un "agraviado" Ramírez de Baquedano que apeló -sin éxito- para que fuese la Real Audiencia, y no el Gobernador, la que legítimamente "hiciese justicia con todo desinterés"79.

En el mismo proceso judicial, el fiscal Gonzalo Ramírez de Baquedano había hallado igualmente infractor al tesorero Mateo del Cajigal y Solar, por "dar favor, ayuda y consejo al situadista para que con diferentes créditos y partidas supuestas diese entero aconsejándole la forma en que las había de suponer" y, en consecuencia, "por haber ayudado a extraviar y defraudar el socorro del ejército que tiene para su defensa" $"$, siendo igualmente embargado de todos sus bienes y papeles y condenado a prisión ${ }^{81}$. En un sumario judicial confidencial, el tesorero fundó su defensa en los "temores concebidos de los daños que podía padecer de mano del gobernador" ${ }^{82}$. Al respecto, en el testimonio de Mateo del Cajigal a instancias del oidor Álvaro Bernardo de Quiroz, aquel alegó que debido a que el situadista "no le expresó si la cantidad de ropa que traía era con orden del gobierno o sin él, [...] escribió este confesante al gobernador", quien respondió no solo aprobando el porte de géneros encauzados desde el virreinato, "sino que le encargó a este confesante se juntase con el capitán Don Pedro de Espejo y el mismo situadista" con objeto de justificar y componer "la materia lo mejor que pudiesen"83. Y así, "Viendo este confesante [Mateo del Cajigal] una demostración tan favorable a dicho situadista cuando esperaba que la respuesta [del gobernador] había de ser castigarle severamente, convino disimular por entonces la falta de dicho situadista, temeroso de que de no hacerlo, [...] había de intentar dicho señor gobernador la ruina de este confesante con la mano y poder absoluto que tiene como lo ha experimentado en otros a quienes ha perseguido" 84 .

En suma, en secreto de confesión, el tesorero Mateo del Cajigal delató a Marín de Poveda de conocer y encubrir al citado situadista. En cualquier caso, el juicio de residencia levantado al gobernador, iniciado, sin embargo, 18 años después de haber concluido su gobierno y fenecido en 1733, reconoció a Marín de Poveda haber

76 Declaración de José Moreno de haberse presentado en prisión. Santiago de Chile, VI-1696. ANH, CG, vol. 855, pieza 19, ff. 340-341.

77 Decreto del gobernador Tomás Marín de Poveda. Santiago de Chile, 23-VIII-1696. ANH, CG, vol. 855, pieza 19, ff. 361 y ss.

78 Real Audiencia sobre la causa criminal contra José Moreno y Mateo del Cajigal y Solar. Santiago de Chile, 30III-1699. AGI, Chile, 103.

79 El fiscal Gonzalo Ramírez de Baquedano al Rey. Santiago de Chile, 15-IV-1699. AGI, Chile, 103.

80 El fiscal Gonzalo Ramírez de Baquedano sobre la causa contra Mateo del Cajigal y Solar. Santiago de Chile, 31-X-1695. ANH, CG, vol. 855, Pieza 19, ff. 195-198v.

81 Decreto de prisión para Mateo del Cajigal y Solar. Santiago de Chile, 28-IV-1695. ANH, CG, vol. 855, pieza 19, ff. 97-98.

82 Declaración de Mateo del Cajigal y Solar. Santiago de Chile, 24-IV-1695. ANH, RA, vol. 2712, pieza 6, ff. 143150 .

83 Declaración de Mateo del Cajigal y Solar. Santiago de Chile, 6-VIII-1695. ANH, RA, vol. 2712, pieza 6, ff. 134-141.

84 Ibídem. 
"atendido con toda satisfacción a los jefes y soldados de este Real Ejercito" 85 , no hallándose en su gobierno, en definitiva, ninguna transgresión a las normas de la monarquía. Tal y como ha señalado Silvina Smietniansky, aquella residencia debe de entenderse como una simple formalidad o "ritual político" ejecutado para hacer referencia "al orden ideal del funcionamiento de las instituciones" 86 de la Corona en territorio americano.

\section{Provocando el fallo en los mecanismos de control: amenazas, violencia e intimidación}

Resta por conocer aquellos mecanismos de los que se sirvió Tomás Marín de Poveda para sortear los sistemas de control institucional en busca de un rédito individual. Así, en primer lugar, valiéndonos del juramento del aludido tesorero Mateo del Cajigal, el gobernador pudo haber coaccionado a las instituciones y a los responsables financieros del Situado susceptibles de haber interceptado y obstruido sus desmanes. En este sentido, antes de iniciar la conducción de aquel segundo socorro llegado a la frontera chilena a principios del año 1693, el situadista José Moreno hubo de dar apremiante y secreto aviso a Marín de Poveda de cómo el corregidor de Potosí, Pedro Luis Henríquez de Guzmán, le estaba inquiriendo sobre la entrega de los 68.000 pesos que hizo a Pedro de Espejo, situadista antecedente, confidente del gobernador y comisionado por entonces de dirigir aquella cantidad al presidio de Buenos Aires, solicitándole "remitiese sin dilación algún instrumento con que defenderse". Y con esa novedad, en suma, acudió con arbitrio Tomás Marín de Poveda a Mateo del Cajigal y Solar con objeto de que le proveyera certificación falsa del libramiento, reconociendo el gobernador que este oficial real, como "custodio de los tesoros del príncipe", tenía la exclusiva competencia en la justificación de los pagos ${ }^{87}$, quien, por su parte, según su propio testimonio, tal y como en líneas anteriores se ha referido, "hubo de convenir a vista del empeño y por obviar mayores inconvenientes en darle la certificación al tenor de su dictamen" $"$.

En cualquier caso, con objeto de eximirse de su implicación en aquel desfalco, considerando, sin embargo, "lo infructuoso que es hacerlo respecto de su absoluto poder y ánimo y condición temeraria", y con la fundada sospecha, además, de que su correspondencia pudiera ser decomisada por el gobernador, Mateo del Cajigal y Solar dio testimonio reservado ante Pedro de Camos y Cevallos, arcediano y vicario general del obispado de Concepción, y ante otros testigos ${ }^{89}$, de los desórdenes que Marín de Poveda estaba ejecutando contra las leyes y mandatos de la Corona. Previno, no obstante, que por su "justo temor" y en predisposición a las "vejaciones" que pudiera sufrir de la misma forma que otros las habían sufrido, habría de "ser forzoso a convenir por ahora en la ejecución de lo que dicho gobernador está ejecutando en su propia utilidad y puro interés y contra el de los milites de este ejército y caudal del Real Situado"90.

Sentencia del Juicio de Residencia al gobernador Tomás Marín de Poveda. ANH, RA, vol. 2979, pieza 4. f. 232.

Smietniansky, 2007: 93. Ver también: Herzog, 2000.

Muñoz, 1992: 100.

Mateo de Cajigal y Solar al rey. Concepción, 16-VIII-1694. ANH, RA, vol. 2712, pieza 6, ff. 159-160v.

89 Entre los firmantes de aquella querella se encontraron el veedor Francisco Jirón de Montenegro, el asentista Francisco García de Sobarzo y Juan Vázquez de Noboa, escribano del cabildo de Concepción.

90 Testimonio de Mateo de Cajigal y Solar ante Pedro de Camos y otros testigos. Concepción, 23-VII-1692. ANH, 
Una resignada y condolida autoinculpación que, a efectos procesales, como verificaría privativamente el tesorero algunos años después, serviría a la Real Audiencia de Chile para apuntalar el pleito criminal ya descrito contra el susodicho oficial del rey.

En efecto, si Marín de Poveda supo ganarse la cooperación de una parte de la oficialidad militar y de los mismos situadistas -agentes ineludibles para la implementación de aquellos negocios prohibidos-, de igual forma eliminó y 'ajustició', como especuló el tesorero, a quienes pudieron haber paralizado sus excesos mediante el uso de la violencia y la extorsión. Tal fue el caso de Pedro de Vergara, regidor del cabildo de Concepción y comisionado por éste en el año 1693 para registrar el trigo que entraba en la ciudad e impedir su exportación ante la suprema necesidad que padecía de él la región y el ejército. Entrando, en este sentido, cierta partida del cereal a nombre del oficial de la Real Hacienda Juan Antonio de Espineda, cómplice del gobernador, quien tenía la pretensión de embarcarla hacia Lima, sucedió un violento enfrentamiento entre este oficial real y Pedro de Vergara, quien intentó entorpecer aquel envío. En esta situación, Marín de Poveda, ante las trabas impuestas a sus intereses mercantiles en torno al trigo por parte del regidor de Concepción, se apresuró a despojarlo de su cargo. Pedro de Vergara, buscando entonces "la justicia de su remedio" ante la Real Audiencia, y "en defensa de ella", finalmente, "perdió la vida ahogándose en el río nombrado Lontué" "91. Y la misma suerte corrió, nos descubre Mateo del Cajigal, el veedor general del ejército de Chile, Francisco Jirón de Montenegro, en 1695: "porque deseaba cumplir con la obligación de su oficio oponiéndose a los dictámenes del dicho señor gobernador y no queriendo pasar ni convenir al desorden de tantos gastos superfluos, [el gobernador] le fulminó [...] en cuya oposición, defensas y demandas perdió la vida dicho veedor general ahogándose en el río nombrado Teno" "92.

Por su parte, también el asentista del ejército Francisco García de Sobarzo, "sin habérsele opuesto en cosa alguna al dicho señor gobernador y solo por haberle pedido una cantidad de plata que le había prestado", hubo de afligirse ante los desafueros y arbitrariedades de Marín de Poveda, que le arrebató los géneros acumulados para el abastecimiento de las guarniciones militares de la frontera chilena y los fletó para su posterior venta en el mercado consumidor del virreinato "dejando a los vecinos y al ejército sin trigo con que mantenerse" ${ }^{" 93}$. Por último, y entre otros damnificados, los alcaldes de Concepción, Juan de Espinosa y Francisco Bello, fueron obligados a retraerse en los conventos de la ciudad "porque supo [el capitán general] informaban al señor virrey del Perú de los procedimientos de dicho gobernador" 94 . De lo que se desprende, en definitiva, el corriente empleo de la violencia, las amenazas y la intimidación por parte de Marín de Poveda, en connivencia con aquellos adeptos que conformaban su red, para la plena satisfacción de sus negocios, y, en consecuencia, la comprensión de los fundados temores de los que se valió el tesorero Mateo del Cajigal y Solar para disculpar sus probados delitos y su participación en torno a los desfalcos perpetrados a los reales Situados.

RA, vol. 2712, pieza 6, ff. 163-164v.

91 Declaración de Mateo del Cajigal y Solar. Santiago de Chile, 6-VIII-1695. ANH, RA, vol. 2712, pieza 6, ff. 134-141.

92 Ibídem.

93 Ibídem.

94 Ibídem. 
En línea con lo anterior, Tomás Marín de Poveda supo, igualmente, paralizar eficientemente las comunicaciones del ya de por sí aislado reino de Chile. En la pesquisa secreta sobre los procedimientos del gobernador levantada por la Real Audiencia en 1694, numerosos testigos dieron cuenta de cómo Marín de Poveda ordenó a los cabos emplazados en el puerto de Concepción, así como en la salida de la ciudad, que ejecutasen los registros convenientes con objeto de requisar la correspondencia que pudiera desvelar sus excesos al virrey del Perú o a las autoridades metropolitanas. Así, el capitán Juan Cisneros de Mendoza declaró saber "que a un cuñado del capitán Juan Calderón que salía de dicha ciudad de la Concepción [le] salió una escuadra de soldados a reconocer si llevaba cartas y que para eso le abrieron todas las petacas" "95. Tenían mandado, de igual forma, llevarlas ante el propio gobernador para que él mismo arbitrase qué escritos podían remitirse y cuáles no. Quizá el lance más conocido, en cualquier caso, fue el ocurrido con el célebre cronista y maestre de campo Jerónimo de Quiroga, cuyos hijos -religiosos franciscanos- hubieron de refugiarle en el convento de dicha orden "para asegurarlo de las violencias de dicho don Tomás Marín de Poveda" 96 después de que soldados enviados por éste requisaran en su casa un baúl repleto de documentos con información que lo comprometían.

Finalmente, puede reseñarse otro hecho igualmente pernicioso para la transparencia en la cobranza del Situado del que supo favorecerse Tomás Marín de Poveda. El mandato de 1687 de remitir el Situado desde la caja de Potosí, y no de la de Lima, vino acompañado de una "Instrucción" que estableció la manera en que había de ejecutarse su distribución, la cual debía ser supervisada por una Junta de Hacienda delegada, entre otras obligaciones, de valerse de los recursos necesarios para sortear el derroche y la defraudación en el desempeño de este cometido. Así, a la llegada del Real Situado debían reunirse en Concepción, convocados por el gobernador y presididos por éste, los oficiales de la Real Hacienda de esta ciudad, el veedor general del ejército, así como el fiscal y el oidor más antiguo de la Real Audiencia emplazada en Santiago. Esto significaba que estos dos agentes de la justicia regia habrían de desplazarse anualmente a Concepción, haciendo frente a los rigores del viaje y, lo que es más relevante, dejando descuidadas por varios meses sus actividades procesales en la capital del reino ${ }^{97}$.

Al respecto, el fiscal Pablo Vázquez de Velasco manifestó en un extenso informe al monarca en 1690 la necesidad de haber estado todo el año "con las espuelas calzadas" y de haber "ocupado siete meses" en el cumplimiento de aquel encargo ${ }^{98}$. Y esta propia evasiva resultó determinante para que el mencionado fiscal y el oidor decano, Bernardo de Laya y Bolívar, resolvieran que "no era necesario para la distribución y paga del real ejército el que pasasen a la dicha ciudad de la Concepción" para el reparto de los dos Situados que se entregaron juntos en 1693, pues en los "viajes de ida, estada y vuelta se ocuparía la mayor parte del año, [...] haciendo faltamiento con ello al principal de su cargo [...] y alterándose en todo la forma de su ministerio y ocupación"'99.

\footnotetext{
95 Declaración del capitán Juan de Cisneros y Mendoza. Santiago de Chile, 17-II-1694. ANH, RA, vol. 2844, pieza 2, ff. 123-132v.

96 Ibídem.

97 Instrucción para la distribución del Real Situado. Madrid, 14-IV-1687. ANH, CG, vol. 717, pieza 56, ff. 84-86v.

98 Informe del fiscal Pablo Vázquez de Velasco al rey. Santiago de Chile, 25-VIII-1690. AGI, Chile, 129.

99 Informe de la Real Audiencia al rey. Santiago de Chile, 6-IV-1696. BN, MM, t. 169, doc. 3518, ff. $173-178$.
} 
Así, la ausencia de ambos agentes de la justicia en la repartición de aquellos dos Situados, movió al gobernador Tomás Marín de Poveda a ejecutar lo convenido en el capítulo quinto de la citada Instrucción, según el cual, habría "de estar en arbitrio del presidente y capitán general nombrar persona que concurra en lugar del que faltase", de manera que el gobernador, en este sentido, hubo de "nombrar personas que sustituyeren sus lugares [...] para ocupar el hueco de tales ministros" $" 100$. Este proceder nos lleva a considerar un mecanismo de defraudación en torno a la distribución del Real Situado a través del cual las 'interinidades' fueron ejercidas por individuos electos arbitrariamente por el gobernador, los cuales, en consecuencia, accedieron a obedecer, negligentemente, lo convenido con este último a partir de las posibilidades de lucro que generó la malversación de unos fondos destinados, en teoría, a la retribución de los soldados.

\section{Consideraciones finales}

Cuando Tomás Marín de Poveda compró en 1683 el cargo de gobernador del Reino de Chile y, en consecuencia, el de presidente de su Real Audiencia, hubo de ambicionar, inferimos, obtener un espacio de poder en las posesiones coloniales americanas que por otra vía no hubiese sido factible. Considerando su gobierno en retrospectiva, recuperar y rebasar aquella incierta inversión parece haberse convertido en una obstinada ambición. En este contexto, haciendo caso omiso a lo que explícitamente la jurisprudencia indiana le preceptuaba, el gobernador advirtió Chile como un mercado que usufructuar, emprendiendo una dinámica implicación en los negocios mercantiles que discurrieron en el reino. Al respecto, el ejército de Chile, y más particularmente, el mecanismo fiscal instaurado para sostenerlo, fue considerado por Marín de Poveda como una de las posibles vías de amortización y beneficio de la que sacó, en efecto, provechos considerables sirviéndose de las prerrogativas dadas por su posición en la jerarquía del reino.

El cambio de consignación de la caja de Lima a la de Potosí en 1687, y la decisión de que el Real Situado se remitiese íntegramente en plata, no obstante, si bien inhabilitó la red limeña que Marín de Poveda integraba a través de su suegro, el comerciante Juan de Urdanegui, marqués de Villafuerte, para la explotación del Situado llegado hasta aquel año en mercancías provistas por los mercaderes de la capital virreinal, propició, sin embargo, inéditas y mayores oportunidades de pujanza y lucro de las que el gobernador supo favorecerse. En este sentido, la nueva coyuntura facilitó una forma de comercio no reglado en la que los situadistas pudieron adquirir productos con el dinero del Situado con los que alcanzar, con su ulterior subasta, los rendimientos suficientes como para, en primer lugar, restituir en la caja de destino la cantidad desfalcada y, en segundo lugar, obtener igualmente un margen de lucro particular. Durante el gobierno de Marín de Poveda, sin embargo, el gobernador no sólo disculpó las citadas tropelías de los situadistas en la conducción de la ayuda, sino que las acució y acaudilló, malversando a su favor los fondos monetarios remitidos como socorro a los soldados.

Amparado por el aislamiento del reino, por la lejanía de los centros de control fiscal, siguiendo únicamente las leyes de su conveniencia y movido por su codi-

100 El gobernador Tomás Marín de Poveda al rey. Concepción, 26-IV-1693. BN, MM, t. 168, doc. 3504, ff. 152-164. 
cia, Marín de Poveda dispuso del Real Situado antes de su entrega en la caja de Concepción para desarrollar negocios y despachos orientados a la obtención de un rendimiento particular. Para ello, toleró y estimuló los abusos de la oficialidad militar; nombró a situadistas a su favor, quienes acataron ciegamente sus instrucciones; torpedeó las comunicaciones; eliminó -y ajustició- a quienes pudieron obstruir sus excesos; y ocasionó, finalmente, la deficiencia de los controles de la administración, ganándose, mediante el arbitrio e intimidación, la cooperación y asistencia pasiva de los oficiales reales. Todo ello, ciertamente, en grave perjuicio de las unidades militares chilenas y contribuyendo, con ello, a debilitar la estabilidad de la frontera y de la propia dominación española en América. En cualquier caso, las dificultades de la caja de Potosí para remitir la subvención (el gobernador solo pudo distribuir tres Situados -dos de ellos, además, requeridos por su antecesor en el cargo- y parte de un cuarto) distinguieron los años de gobernación de Marín de Poveda; y esta coyuntura desfavorable imposibilitó que el ejército, y su Real Situado, se constituyesen, como tal vez pudo discurrir el gobernador al inicio de su administración, en su única y gran vía de enriquecimiento particular.

El presente artículo, no obstante, lejos de presentar conclusiones acabadas y definitivas sobre las prácticas corruptas del gobernador Marín de Poveda en el manejo del Real Situado y, en última instancia, acerca del estudio del ejército de la frontera como elemento de explotación y de comercio del que se valió el gobernador para su riqueza personal, constituye, a nuestro entender, el punto de partida sobre el que desarrollar una indagación futura más exhaustiva. Al respecto, partiendo de la base probada de que para proceder de forma sólida y estable el gobernador hubo de establecer vínculos con otros actores sociales, consideramos que para cerrar el círculo de los objetivos planteados se hace ineludible identificar, representar y definir con precisión la serie de intercambios relacionales del gobernador a partir de los cuales Marín de Poveda se sirvió para generar su fortuna; reflexionar, igualmente, acerca de la influencia del gobernador en estos vínculos y de estos vínculos en el gobernador; y, en definitiva, indagar la forma en que las redes generadas lograron influir en el comportamiento de las instituciones y en las decisiones políticas-económicas en torno al Real Situado.

\section{Referencias bibliográficas}

Abarca Aguirre, Jorge. "La corrupción burocrática: corruptos, delitos y justicia en Chile colonial (1621-1700)". Tesis doctoral, Universidad de Chile, 2010.

Alioto, Sebastián Leandro. "La rebelión indígena de 1693: desnaturalización, violencia y comercio en la frontera de Chile". Anuario de Estudios Americanos, vol. $71, n^{\circ} 2$ (2014), 503-537.

Andújar Castillo, Francisco. El sonido del dinero: Monarquía, ejército y venalidad en la España del siglo XVIII. Madrid: Marcial Pons, 2004.

— "Empresarios de la guerra y asentistas de soldados en el siglo XVII". En Guerra y sociedad en la monarquía hispánica: política, estrategia y cultura en la Europa moderna (1500-1700), editado por García Hernán, Enrique - Maffi, Davide. Madrid: Fundación Mapfre - Ediciones Laberinto - CSIC, 2006, 375-394. 
— "Tiempo de venalidad. Tomás Marín de Poveda y la venta de cargos de Indias". En Riqueza, poder y nobleza: los Marín de Poveda, una historia familiar del siglo XVII vista desde España y Chile, coordinado por Andújar Castillo, Francisco - Giménez Carrillo, Domingo Marcos. Almería: Universidad de Almería, 2011, 79-92.

Andújar Castillo, Francisco - Giménez Carrillo, Domingo Marcos (coords.). Riqueza, poder y nobleza: los Marín de Poveda, una historia familiar del siglo XVII vista desde España y Chile. Almería: Universidad de Almería, 2011.

Andújar Castillo, Francisco - Felices de la Fuente, $M^{a}$ del Mar. "El poder de una familia: los Marín de Poveda, de Lúcar (Almería) a Chile en el siglo XVII". En Riqueza, poder y nobleza: los Marín de Poveda, una historia familiar del siglo XVII vista desde España y Chile, coordinado por Andújar Castillo, Francisco - Giménez Carrillo, Domingo Marcos. Almería: Universidad de Almería, 2011, 15-32.

- El poder del dinero: ventas de cargos y honores en el Antiguo Régimen. Madrid: Biblioteca Nueva, 2011b.

Barros Arana, Diego. Historia General de Chile, tomo IV. Santiago de Chile: Universitaria - Centro de Investigación Barros Arana, 2005.

Bertrand, Michel. Grandeur et misères de l'office: les officiers de finances de Nouvelle-Espagne (XVIIe-XVIIIe siècles). París: Université de Paris I, Panthéon-Sorbonne, 1999.

- "Viejas preguntas, nuevos enfoques: la corrupción en la administración colonial española". En El poder del dinero: venta de cargos y honores en el Antiguo Régimen, editado por Andújar Castillo, Francisco - Felices de la Fuente, $\mathrm{M}^{\mathrm{a}}$ del Mar. Madrid: Biblioteca Nueva, 2011, 46-62.

Campos Harriet, Fernando. Historia General de Concepción: 1550-1970. Santiago de Chile: Editorial Universitaria, 1982.

Carmagnani, Marcello. Los mecanismos de la vida económica de una sociedad colonial. Chile (1680-1880). Santiago de Chile: Centro de Investigaciones Diego Barros Arana, 2001.

Carvallo Goyeneche, Vicente. Descripción histórico-geográfica del Reino de Chile, tomo II. Santiago de Chile: Imprenta de la Librería del Mercurio, 1875.

Celaya Nández, Yovana. Alcabalas y situados: Puebla en el sistema fiscal imperial, 1638-1742. México: Colegio de México Fideicomiso Historia de las Américas, 2010.

Cerda Hegerl, Patricia. Fronteras del Sur. La región del Bio Bio y la Araucanía chilena. 1604-1883. Temuco: Universidad de la Frontera, 1996.

Coello de la Rosa, Alexandre. "Corrupción, codicia y mal gobierno en las Islas Marianas (1700-1730)". Illes Imperis, vol. 16 (2014), 39-70.

Díaz Blanco, José Manuel. Razón de Estado y buen gobierno. La Guerra Defensiva y el imperialismo español en tiempos de Felipe III. Sevilla: Secretariado de Publicaciones de la Universidad de Sevilla, 2010.

Ferrando Keun, Ricardo. Y así nació la frontera: conquista, guerra, ocupación, pacificación, 1500-1900. Santiago de Chile: Eds. Universidad Católica de Temuco, 2012.

Flores Guzmán, Ramiro Alberto. "Los situados peruanos: desde Chile hasta Panamá, 1700-1800". En El secreto del Imperio español: los situados coloniales en el siglo XVIII, coordinado por Marichal, Carlos - Grafenstein, Johanna von. México: Centro de Estudios Históricos, El Colegio de México - Instituto Mora, 2012, 33-61.

Flores Morón, Braulio Luis. "Los situados del Río de la Plata en el siglo XVIII". Temas de Historia Militar, vol. 2 (1988), 207-220. 
Gascón, Margarita. "La articulación de Buenos Aires a la frontera sur del Imperio español, 1640-1740”. Anuario Instituto de Estudios Histórico y Sociales, vol. 13 (1998), 193-213.

- "Comerciantes y redes mercantiles del siglo XVII en la frontera sur del Virreinato del Perú". Anuario de Estudios Americanos, vol. 57, no 2 (2000), 413-448.

— "La defensa del sur del virreinato del Perú en el siglo XVII: la estrategia imperial y la agencia de la naturaleza". Revista TEFROS, vol. 6, nº 1 (2008), 1-20.

Gaune Corradi, Rafael. Escritura y salvación: cultura misionera Jesuita en tiempos de Anganamón, siglo XVII. Santiago de Chile: Ediciones Universidad Alberto Hurtado - Instituto de Historia, Pontificia Universidad Católica de Chile, 2016.

Grafenstein, Johanna von. "El papel de la Nueva España como fuente de recursos para las posesiones españolas del Gran Caribe (1779-1784)". Homines. Revista de Ciencias Sociales, vol. 20, no 2 (2000), 338-355.

- "Situado y gasto fiscal: la real caja de México y las remesas para gastos militares en el Caribe, 1756-1787'. En Guerra y Fiscalidad en la América colonial, siglos XVI-XIX, coordinado por Alves Carrara, Ángelo - Sánchez Santiró, Ernest. México: Instituto Mora - Universidad Federal Juiz de Fora, 2012, 115-142.

Herzog, Tamar. "Ritos de control, prácticas de negociación: pesquisas, visitas y residencias y las relaciones entre Quito y Madrid". En Nuevas Aportaciones a la Historia Jurídica de Iberoamérica (CD-Rom), coordinado por Andrés-Gallego, José. Madrid: Fundación Histórica Tavera, 2000. Disponible en www.larramendi. es/i18n/catalogo_imagenes/grupo.cmd?path=1000181.

Irigoin, Alejandra - Grafe, Regina. "Bargaining for Absolutism. A Spanish Path to Nation-State and Empire Building". The Hispanic American Historical Review, vol. $88, \mathrm{n}^{\mathrm{o}} 2$ (2008), 235-245.

Jara Hantke, Álvaro. Guerra y sociedad en Chile: la transformación de la Guerra de Arauco y la esclavitud de los Indios. Santiago de Chile: Ed. Universitaria, 1971.

- El Imperio español en América (1700-1820). Una historia económica. Santiago de Chile: Editorial Sudamericana, 2011.

Kraselsky, Javier. "Conflictos corporativos entre comerciantes en el virreinato del Río de la Plata. La conducción de caudales de Potosí a Buenos Aires, 17951803". Americanía. Revista de Estudios Latinoamericanos, no 4 (2016), 215-246.

Kuethe, Allan J. "Guns, Subsidies and Commercial Privilege: Some Historical Factors in the Emergence of the Cuban National Character, 1763-1815". Cuban Studies, $\mathrm{n}^{\mathrm{o}} 16$ (1986), 123-138.

— "El situado mexicano, los azucareros y la fidelidad cubana". En Las Antillas en la era de las Luces y la revolución, editado por Piqueras Arenas, José Antonio. Castellón de la Plana: Siglo XXI, 2005, 301-318.

Laviana Cuetos, María Luisa. Organización y funcionamiento de las Cajas Reales de Guayaquil en la segunda mitad del siglo XVIII. Sevilla: Escuela de Estudios Hispanoamericanos, CSIC, 1980.

- Excedente fiscal y defensa del Imperio: el situado de Guayaquil a Cartagena en el siglo XVIII. Varsovia: University of Warsaw, 2000.

— "Excedente fiscal y defensa del Imperio: el situado de Guayaquil a Cartagena en el siglo XVII". Revista del CESLA, no 11 (2008), 93-104.

León Solís, Leonardo. "Malocas araucanas en las fronteras de Chile, Cuyo y Buenos Aires, 1700-1800". Anuario de Estudios Americanos, no 44 (1987), 281-234.

— "Maloqueros, tráfico ganadero y violencia en las fronteras de Buenos Aires, Cuyo 
y Chile, 1700-1800". Jahrbuch für Geschichte Lateinamerikas = Anuario de Historia de América Latina, $\mathrm{n}^{\circ} 26$ (1989), 37-83.

- Maloqueros y conchavadores: en Araucanía y las pampas, 1700-1800. Temuco: Universidad de la Frontera, 1992.

Marchena Fernández, Juan. "La financiación militar en Indias: introducción a su estudio". Anuario de Estudios Americanos, no 36 (1979), 81-110.

- La institución militar en Cartagena de Indias en el siglo XVIII (1700-1810). Sevilla: Centro Superior de Investigaciones Científicas, 1982.

- Ejército y milicias en el mundo colonial americano. Madrid: Mapfre, 1992.

— "Financiación militar y situados". Temas de Historia Militar, vol. 1 (1998), 261-310.

Marichal, Carlos - Souto Mantecón, Matilde. "Silver and Situados: New Spain and the Financing of the Spanish in the Caribbean in the XVIII century". The Hispanic American Historical Review, vol. 74, $\mathrm{n}^{\circ} 4$ (1994), 587-613.

Marichal, Carlos - Grafenstein, Johanna von. El secreto del Imperio español: los situados coloniales en el siglo XVIII. México: Instituto Mora, 2012.

McFarlane, Anthony. "Political corruption and reform in Bourbon Spanish America". En Political corruption in Europe and Latin America, editado por Little, Walter - Posada-Carbó, Eduardo. London: Institute of Latin American Studies Series - University of London, 1996, 41-63.

Meisel Roca, Adolfo. "Crecimiento a través de los subsidios: Cartagena de Indias y el situado, 1751-1810". Cuadernos de Historia Económica y Empresarial, no 9 (2002), 1-26.

— “Situado o contrabando? La base económica de Cartagena de Indias a finales del siglo de las Luces". En Cartagena de Indias en el siglo XVIII, editado por Calvo Stevenson, Haroldo. Cartagena de Indias: Banco de la República, 2005.

Méndez Beltrán, Luz María. "Trabajo indígena en la frontera araucana de Chile". Jahrbuch für Geschichte Lateinamerikas = Anuario de Historia de América Latina, $\mathrm{n}^{\circ} 24$ (1987), 213-249.

Moutoukias, Zacarías. "Power, Corruption and Commerce: The Making of the Local Administrative Structure in Seventeenth-Century Buenos Aires". The Hispanic American Historical Review, vol. 68, $\mathrm{n}^{\circ} .4$ (1988a), 771-801.

- "Burocracia, contrabando y autotransformación de las élites: Buenos Aires en el siglo XVII". Anuario IEHS: Instituto de Estudios Históricos Sociales, n ${ }^{\circ} 3$ (1988b), 213-248.

— "Una forma de oposición: el contrabando". En Gobernare il mondo. L'Impero Spagnolo dal XV al XIX secolo, coordinado por Ganci, Massimo - Romano, Ruggiero. Palermo: Societá Siciliana per la Storia Patria - Instituo di Storia Moderna - Facoltá di Lettere, 1991, 333-367.

Muñoz Correa, Juan Guillermo (ed.). Instituciones y funcionarios en Chile Colonial. Santiago de Chile: Universidad de Chile, 1992.

Obregón Iturra, Jimena Paz. "Rituels et conflicts: Hispano-Créoles et Araucans-Mapuches dans le Chili colonial (fin du 17ème siècle). Avec l'éd critique d'actes judiciaires. Concepción 1693-1695”. Tesis doctoral, Universidad de Rennes, 2003.

- "Claves de un encumbramiento exitoso y de una política indígena emprendedora: los parlamentos hispano - indígenas de Tomás Marín de Poveda (Chile, 16921694). En Riqueza, poder y nobleza: los Marín de Poveda, una historia familiar del siglo XVII vista desde España y Chile, coordinado por Andújar Castillo, Francisco - Giménez Carrillo, Domingo Marcos. Almería: Universidad de Almería, 
2011, 93-114.

- Des indiens rebelles face à leurs juges. Espagnols et araucans-mapuches dans le Chili colonial, fin XVIIe siècle. Rennes: Presses Universitaires de Rennes, 2015. Oñat, Roberto. Régimen legal del ejército en Chile: notas para su estudio. Santiago de Chile: Ed. Del Pacífico, 1953.

Pacheco Díaz, Argelia. Una estrategia imperial. El situado de España a Puerto Rico, 1765-1821. San Juan de Puerto Rico: Instituto Mora, 2005.

Pietschmann, Horst. "Burocracia y corrupción en Hispanoamérica colonial". Nova Americana, $\mathrm{n}^{\circ} 5$ (1982), 11-37.

— "Corrupción en las indias españolas: revisión de un debate en la historiografía sobre Hispanoamérica colonial". En Instituciones y corrupción en la historia, editado por González Jiménez, Manuel - Pietschmann, Horst - Comin, Francisco - Pérez, Joseph. Valladolid: Universidad de Valladolid, 1998, 31-52.

— "Corrupción en el virreinato novohispano: un tercer intento de valoración". ESpania, (2013). Disponible en https://e-spania.revues.org/22848.

Pinto Rodríguez, Jorge. Misioneros en la Araucanía, 1600-1900: un capitulo de historia fronteriza en Chile. Temuco: Universidad de la Frontera, 1988.

— "Jesuitas, franciscanos y capuchinos italianos en La Araucanía (1600-1900)". Revista Complutense de Historia de América, no 19 (1993), 677-698.

- Frontera, misiones y misioneros en La Araucanía, 1600-1900. Temuco: Ed. Universidad de La Frontera, 2015.

Ponce Leiva, Pilar - Andújar Castillo, Francisco (coords.). Mérito, venalidad y corrupción en España y América, siglos XVII y XVIII. Valencia: Albatros, 2016.

Ponce Leiva, Pilar. "Percepciones sobre la corrupción en la Monarquía Hispánica, siglos XVI y XVII". En Mérito,venalidad y corrupción en España y América. Siglos XVII y XVIII, editado por Ponce Leiva, Pilar - Andújar Castillo, Francisco. Valencia: Albatros, 2016, 193-211.

Quiroz, Alfonso. Historia de la corrupción en el Perú. Lima: IEP Ediciones, 2013.

Ramón, Armando de. Historia urbana: una metodología aplicada. Santiago de Chile: CLACSO-SIAP, 1978.

Ramón, Armando de - Larraín, José Manuel. Orígenes de la vida económica chilena. Santiago de Chile: C. E. P., 1982.

Recopilación de las Leyes de los Reinos de Indias [1680]. Madrid: Boix editor, 1841.

Reichert, Rafael. "El situado novohispano para la manutención de los presidios españoles en la región del Golfo de México y el Caribe durante el siglo XVII". Estudios de Historia Novohispana, vol. 46 (2012), 47-81.

Retamal Favereau, Julio. Familias fundadoras de Chile, 1601-1655. El segundo contingente. Santiago de Chile: Ediciones Universidad Católica de Chile, 2000.

Rosenmüller, Christoph. Patrons, Partisans and Palace Intrigues: the Court Society of Colonial Mexico, 1702-1710. Calgary: The University of Calgary Press, 2008.

— "El grave delito de... corrupción: la visita de la Audiencia de México (17151727) y las repercusiones internas de Utrecht". En Resonancias imperiales en América y la Paz de Utrecht de 1713, coordinado por Escamilla González, Iván - Souto Mantecón, Matilde - Pinzón Ríos, Guadalupe. México: Instituto de Investigaciones Mora - UNAM, 2016a, 79-118.

- "Corrupted by ambition. Justice and Patronage in Imperial New Spain and Spain, 1650-1755”. Hispanic American Historical Review, vol. 96, no 1 (2016b), 1-37. DOI: $10.1215 / 00182168-3423868$. 
Ronsenmüller, Christoph - Ruderer, Stephan (eds.). Dádivas, dones y dineros: aportes a una nueva historia de la corrupción en América Latina desde el imperio español a la modernidad. Madrid: Iberoamericana - Vervuert, 2016.

Ruíz-Esquide Figueroa, Andrea. Los indios amigos en la frontera araucana. Santiago de Chile: DIBAM - Centro de Investigaciones Diego Barros Arana, 1993.

Ruiz Rivera, Julián - Sanz Tapia, Ángel (coords.). La venta de cargos y el ejercicio del poder en Indias. León: Universidad de León, Secretariado de Publicaciones, 2007.

Saguier, Eduardo R. "La corrupción administrativa como mecanismo de acumulación y engendrador de una burguesía comercial local". Anuario de Estudios Americanos, $\mathrm{n}^{\circ} 46$ (1989a), 269-303.

- "La conducción de los caudales de oro y plata como mecanismo de corrupción. El caso del Situado asignado a Buenos Aires por las cajas reales de Potosí en el siglo XVIII". Historia, vol. 24 (1989b), 287-317.

- "La corrupción de la burocracia colonial borbónica y los orígenes del federalismo: el caso del Virreinato del Río de la Plata". Jahrbuch für Geschichte Lateinamerikas = Anuario de Historia de América Latina, $\mathrm{n}^{\circ} 29$ (1992), 149-177.

Sanz Tapia, Ángel. "Andaluces en cargos políticos hispanoamericanos (1674-1700)". En Estudios sobre América, siglos XVI-XX, coordinado por Gutiérrez Escudero, Antonio - Laviana Cuetos, María Luisa. Sevilla: Asociación Española de Americanistas, 2005, 613-632.

- ¿Corrupción o necesidad? La venta de cargos de gobierno americanos bajo Carlos II (1674-1700). Madrid: CSIC, 2009.

- "La justicia en venta. El beneficio de cargos americanos de audiencia bajo Carlos II (1683-1700)". Anuario de Estudios Americanos, vol. 69, no 1 (2012), 63-90.

Serrano Álvarez, José Manuel. "El situado en la administración militar indiana: los casos de Santa Fe y Quito, 1700-1788”. Revista de Historia Militar, n 92 (2002), 147-184.

- Fortificaciones y tropas: el gasto militar en Tierra Firme, 1700-1788. Sevilla: Universidad de Sevilla; Centro Superior de Investigaciones Científicas; Diputación de Sevilla, 2004a.

- "Situados y rentas en Cartagena de Indias durante el siglo XVIII". Temas Americanistas, $\mathrm{n}^{\circ} 17$ (2004b), 58-78.

— "Situados y administración militar en Texas a mediados del siglo XVIII". Temas Americanistas, $\mathrm{n}^{\circ} 18$ (2005), 40-55.

- Ejército y fiscalidad en Cartagena de Indias: ange y declive en la segunda mitad del siglo XVII. Bogotá: El Áncora, 2006a.

— "Economías, rentas y situados en Cartagena de Indias, 1761-1800". Anuario de Estudios Americanos, vol. 63, nº 2 (2006b), 75-96.

Silva Vargas, Fernando. "Perú y Chile. Notas sobre sus vinculaciones administrativas y fiscales (1785-1800)". Historia, vol. 7 (1968), 147-203.

— "Los gobernadores como agentes estructuradores de la sociedad chilena en los siglos XVII y XVIII". Boletín de la Academia Chilena de la Historia, $\mathrm{n}^{\circ} 116$ (2007), 177-218.

- Poder y redes: el gobernador de Chile don Francisco Ibáñez de Peralta (17001709). Santiago de Chile: Academia Chilena de la Historia, 2013.

Smietniansky, Silvina. "El juicio de residencia como ritual político en la colonia (Gobernación de Tucumán, siglo XVIII)". Memoria Americana, $\mathrm{n}^{\circ} 15$ (2007), 71-101.

Suárez, Margarita. Comercio y fraude en el Perú colonial: las estrategias mercantiles de un banquero. Lima: Instituto de Estudios Peruanos, 1995.

- Desafios transatlánticos: mercaderes, banqueros y el estado en el Perú virreinal, 
1660-1700. Lima: Pontificia Univ. Católica del Perú - Inst. Riva-Agüero, 2001.

TePaske, John. La Real Hacienda de Nueva España, la Real Caja de México: 15761816. México: Instituto Nacional de Antropología e Historia, 1976.

TePaske, John - Klein, Herbert S. The Royal Treasuries of the Spanish Empire in America. Durham: N.C. Duke University Press, 1982.

- Ingresos y egresos de la Real Hacienda de Nueva España. Culhuacán: Instituto Nacional de Antropología e Historia, 1988.

Torres Sánchez, Jaime. "La Real Hacienda del Reino de Chile y los gastos militares". Nueva Historia, vol. 2, nº 6 (1983), 111-129.

Urbina Carrasco, María Ximena. La frontera de arriba en Chile colonial: interacción hispano-indígena en el territorio entre Valdivia y Chiloé e imaginario de sus bordes geográficos, 1600-1800. Valparaíso: Pontificia Universidad Católica de Valparaíso, 2009.

Vargas Cariola, Juan Eduardo. "Los Austrias y el ejército de Chile en el siglo XVII". Revista Chilena de Historia del Derecho, no 9 (1983), 355-370.

— "Financiamiento del Ejército de Chile en el siglo XVII". Historia, no 19 (1984), 159-202.

- "Antecedentes sobre levas en Indias para el ejército de Chile en el siglo XVII (1541-1662)". Historia, vol. 22 (1987), 335-356.

- "Notas sobre el gobierno militar en Indias: el caso del ejército de Chile en el siglo XVII”. Revista Chilena de Historia del Derecho, vol. 15 (1991), 219-234.

— "Estilo de vida en el Ejército de Chile durante el siglo XVII". Revista de Indias, vol. 51 (1992), 425-458.

Vásquez Ríos, Pablo. "El pueblo mapuche y sus relaciones fronterizas: de España a Chile, entre resistencia y asimilación". TRIM: revista de investigación multidisciplinar, $\mathrm{n}^{\mathrm{o}} 4$ (2012), 87-98.

Vergara Quiroz, Sergio. Historia social del ejército de Chile. Santiago de Chile: Universidad de Chile, 1993.

Villalobos, Sergio. Relaciones fronterizas en la Araucanía. Santiago de Chile: Universidad Católica de Chile, 1982.

- Los Pehuenches en la vida fronteriza. Santiago de Chile: Univ. Católica de Chile, 1989.

- La vida fronteriza en Chile. Madrid: Mapfre, 1992.

- Vida fronteriza en la Araucanía: el mito de la Guerra de Arauco. Santiago de Chile: Andrés Bello, 1995.

- La Araucanía: historia y falsedades. Santiago de Chile: Universidad Bernardo O’Higgins, 2015.

Villalobos, Sergio - Pinto Rodríguez, Jorge. Araucanía: temas de historia fronteriza. Santiago de Chile: Ed. Universidad de La Frontera, 1985.

Waquet, Jean-Claude. Corruption: Ethics and Power in Florence, 1600-1770. University Park: Pennsylvania State University Press, 1991.

Wasserman, Martín L. "El Real Situado y gestión patrimonial del recurso fiscal. Remesas para la defensa del puerto de Buenos Aires en el siglo XVII". Nuevo Mundo Mundos Nuevos, $\mathrm{n}^{\mathrm{o}}$ (2016). Disponible en https://nuevomundo.revues. org/69317.

Zavala Cepeda, José Manuel. Los parlamentos hispano-mapuches, 1593-1803: textos fundamentales. Temuco: Universidad Católica de Temuco, 2015. 